\title{
FASHION DESIGN OF SILHOUETTES WITH THE USE OF 3D ELEMENTS
}

\author{
Petya Dineva, Julieta llieva \\ Faculty of Technics and Technologies of Yambol, \\ Trakia University of Stara Zagora, Bulgaria \\ Graf Ignatiev 38, 8600 Yambol, Bulgaria \\ e-mail: petya.dineva@trakia-uni.bg, zhulieta.ilieva@trakia-uni.bg
}

\begin{abstract}
An investigation of the possibility of fashion design of the different type of silhouettes with the use of $3 D$ elements is the main aim of the paper. The silhouettes are non-volumetric and volumetric and $3 D$ elements are more suitable for design of volumetric ones. For the realization of the purpose models of ladies' dresses in different types of volumetric silhouettes with the use of different types of 3D elements are designed.

One more silhouette - combined one can be added to the classification of the silhouettes. This type of silhouette can be combination between volumetric and non-volumetric shapes, or mixture of only volumetric ones. Every type of 3D elements can be used in design of volumetric silhouettes. And these types are: draperies; one-sided, bi-sided, and covered tucks; gathers, one-sided, bi-sided, and covered plates; goffers; ruffles; ribbons. 3D elements can be used in the fashion design of different types of silhouettes as elements which combined decorative and constructional function, or as only decorative ones.
\end{abstract}

Keywords: fashion design, silhouettes, 3D elements, ladies' dresses.

\section{INTRODUCTION}

The silhouettes of the ladies' clothing are twelve [1, 2] and they are defined by their level of fitting at the waist, and can be marked with geometrical shapes, letters, or objects. According to their fitting at the body shape the silhouettes can be determined as non-volumetric and volumetric ones. Non-volumetric silhouettes, presented in Figure 1, are these which usually are defined by their fitting at the waist. They are close fitted at the bust and waist, fitted at the waist, semi fitted at the waist, and non-fitted at the waist. In the volumetric silhouettes, shown n Figure 2 and 3, some parts are with the shapes which are bigger than the relevant form of the human body. They are usually determined by geometrical shapes, letters and objects. These of them, which are fitted at the waist and presented in Figure 2, are Y, Y turned, X, Flower, and Vase. These of them, which are non-fitted at the waist and shown in Figure 3, are $\mathrm{A}, \mathrm{O}$, and $\mathrm{V}$ forms. One of the ways for design of the different types of silhouettes is the use of 3D elements. But 3D elements are more suitable for fashion design of volumetric silhouettes.

An investigation of the possibility of design of the different type of silhouettes with the use of $3 \mathrm{D}$ elements is the main aim of the paper. For the realization of the purpose models of ladies' dresses in different types of volumetric silhouettes with the use of different types of 3D elements are designed. 


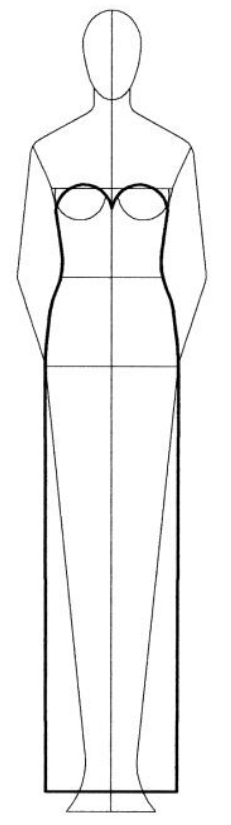

Close fitted at the bust and waist

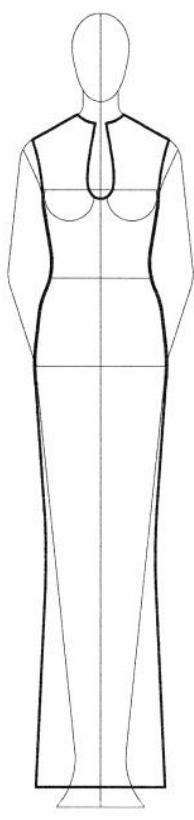

Fitted at the waist

Figure 1. Non-volumetric silhouettes

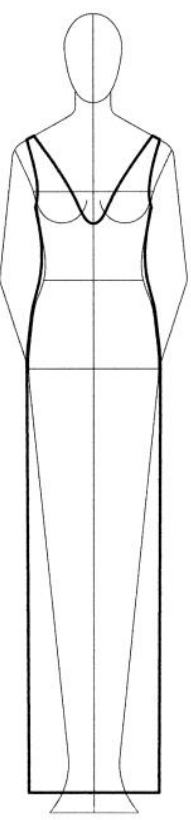

Semi fitted at the waist

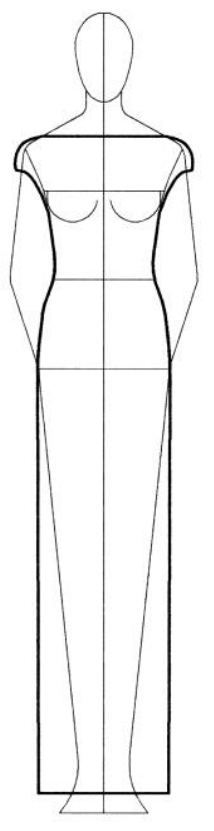

Y

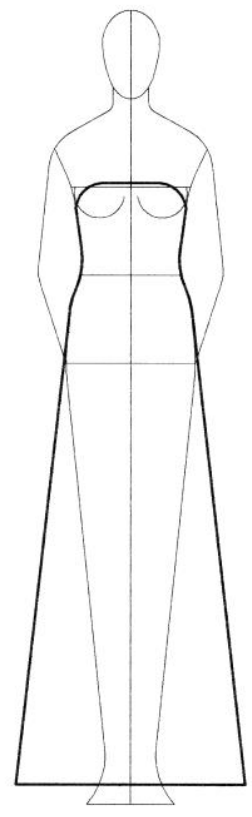

Y turned

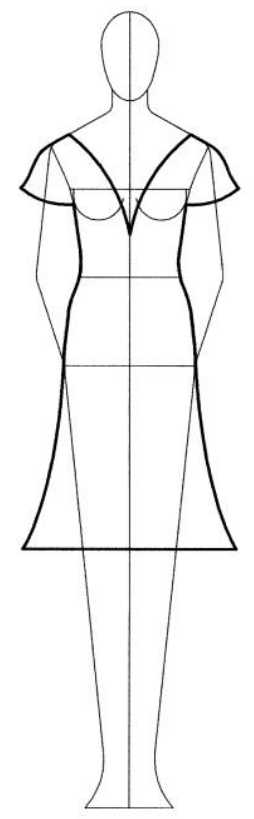

$x$

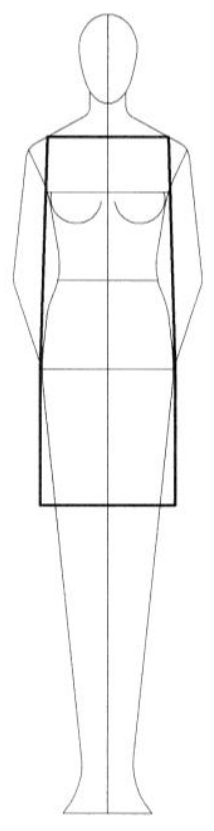

Non-fitted at the waist

Figure 2. Volumetric fitted at the waist silhouettes 


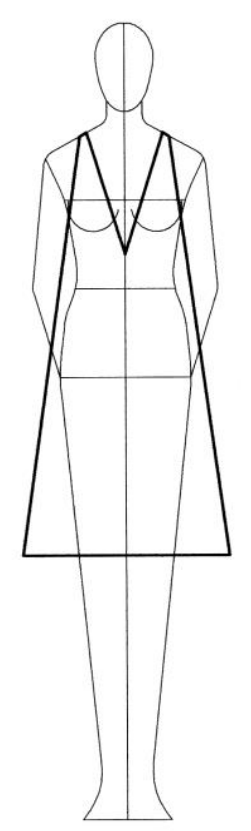

A

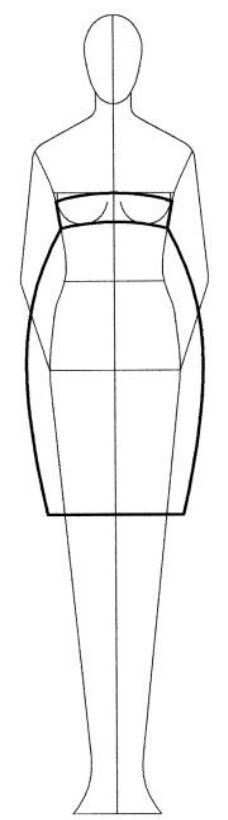

$\mathrm{O}$

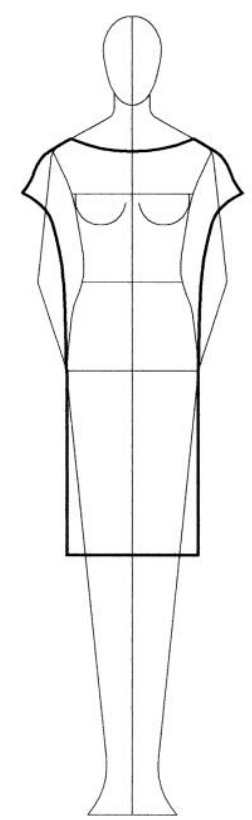

V

Figure 3. Volumetric non-fitted at the waist silhouettes

\section{THE USE OF 3D ELEMENTS FOR DESIGN OF DIFFERENT TYPES OF SILHOUETTES}

Figure 4 presents a lady's dress in $Y$ shape silhouette. The $Y$ form is a result of volumetric sleeves with a lot of ruffles.

Figure 5 presents a model of a lady's dress in $Y$ turned silhouette. The $Y$ turned form is designed by mixed one-sided and bi-sided plates, which are partially sewing on under the waist.

Figure 6 shows a lady's dress in X form silhouette. The down part of the model is designed with bi-sided plates.

Figure 7 shows a model of a lady's dress in $X$ shape silhouette. The down part of the silhouette is formed with bi-side plates which are partially covered each on other.

Figure 8 presents a lady's dress in X shape silhouette. The down part of the model is designed with goffers. The upper part of the dress combines $V$ form neckline with ribbons on the shoulders.

Figure 9 shows a model of a lady's dress in silhouette, which is named 'flower'. The expansive volumetric down part of the dress is formed with the use of deep mixed one-sided and bi-sided plates, which are partially sewing on under the waist.

Figure 10 presents a lady's dress in 'flower' silhouette too. The expansive volumetric down part of the model is a result of an intensive gather. The volumetric down part of the dress is underlined by a big ribbon.

Figure 11 presents a lady's dress in silhouette 'vase'. The volumetric down part of the model is designed by bi-sided tucks.

Figure 12 shows a model of a lady's dress in 'vase' silhouette. The silhouette's form is a result of one-sided tucks.

Figure 13 presents a lady's dress in A form silhouette, which is a result of goffers.

IRTIIE Vol. 4, No. 2, 2016 ISSN 1314-8788 (print), ISSN 1314-8796 (online), doi: 10.15547/artte.2016.02.001 


\section{IRTTIE}

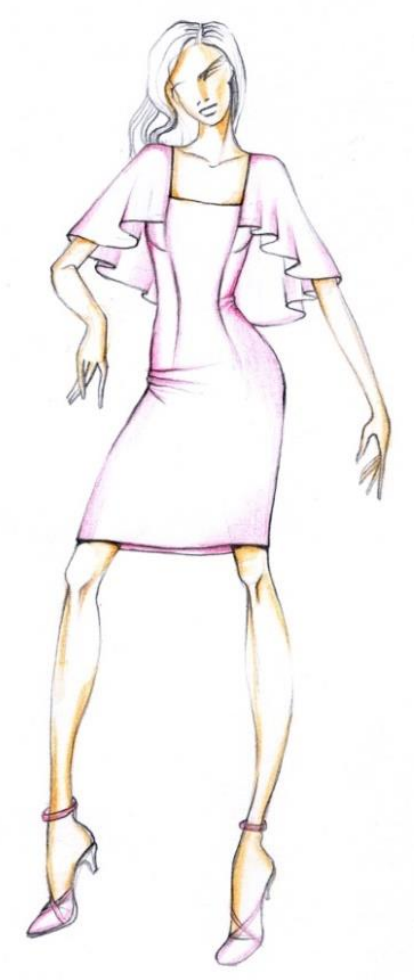

Figure 4. Y form silhouette, designed with ruffles

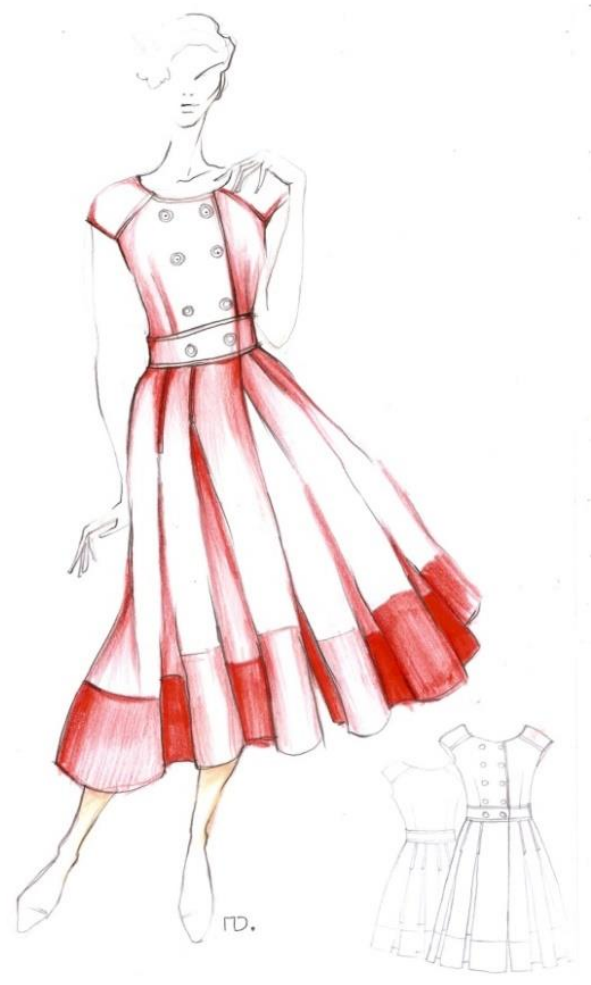

Figure 7. X silhouette with bi-sided partially covered plates

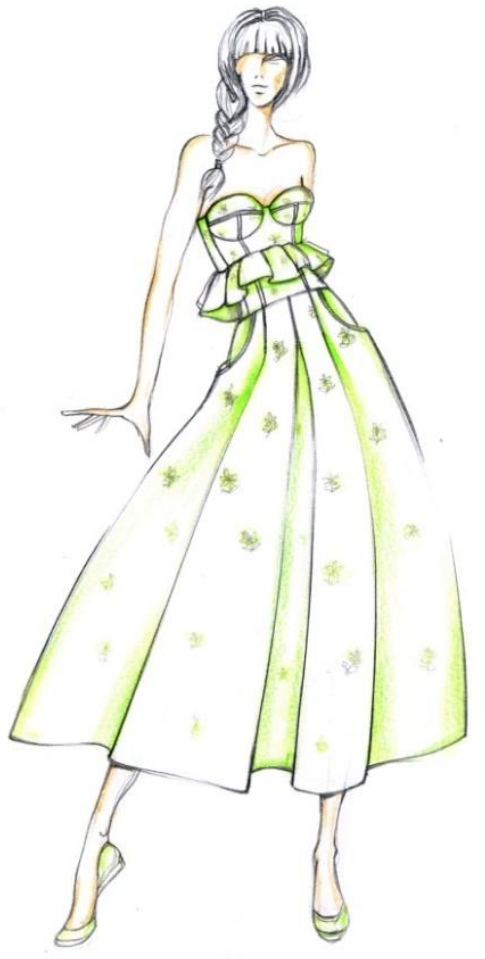

Figure 5. Y turned silhouette with one- and bi-sided plates

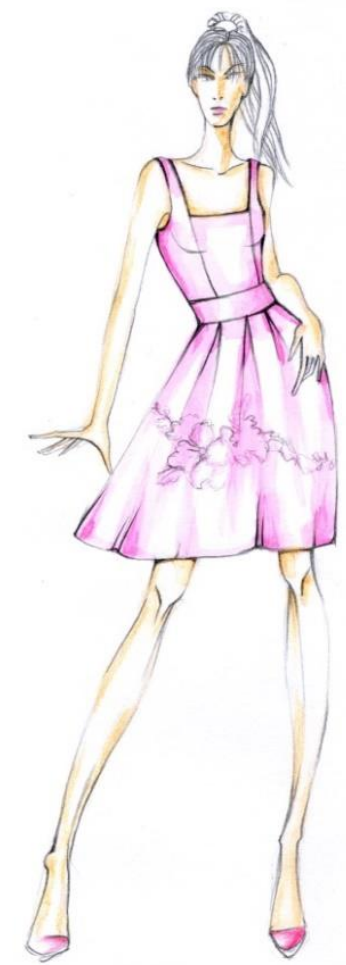

Figure 6. X silhouette with bi-sided plates

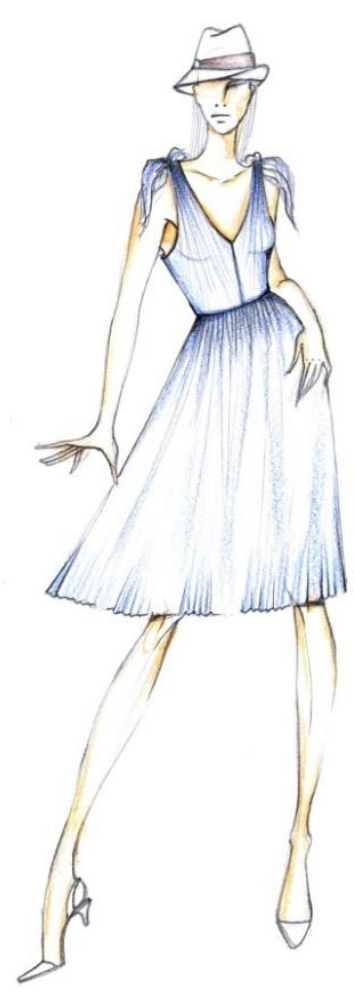

Figure 8. X silhouette with goffers in the down part and ribbons in the upper part

IRTIIE Vol. 4, No. 2, 2016 ISSN 1314-8788 (print), ISSN 1314-8796 (online), doi: 10.15547/artte.2016.02.001 


\section{ARTIIE Y}

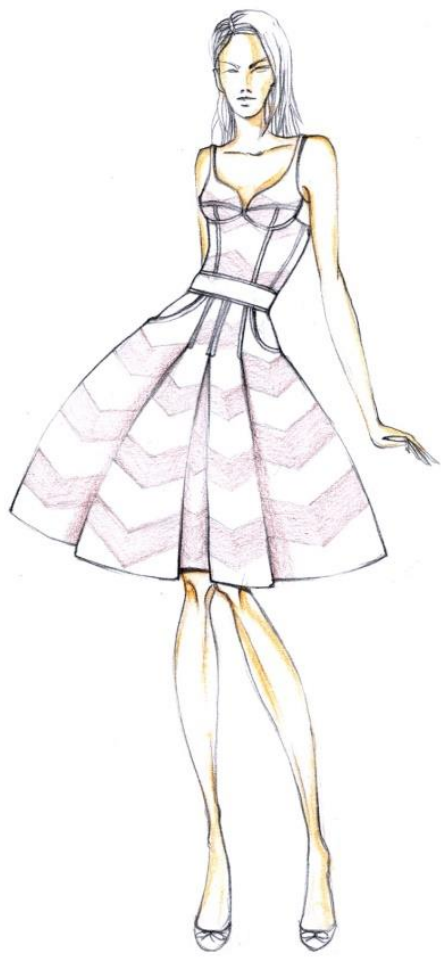

Figure 9. Silhouette 'flower' with deep oneand bi-sided plates

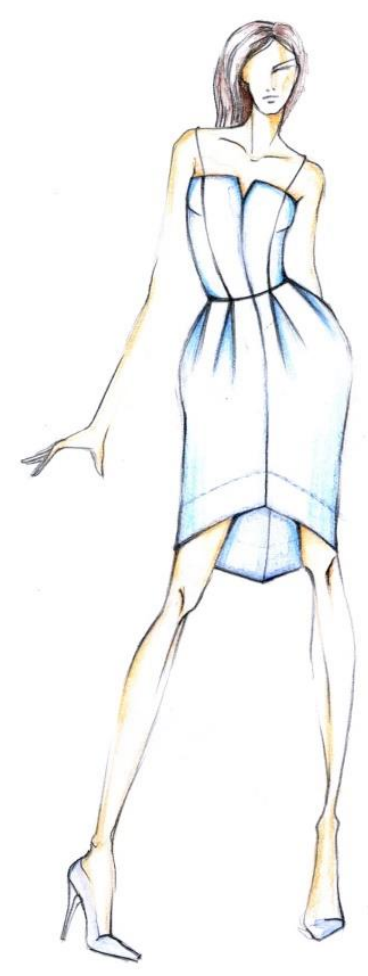

Figure 11. Silhouette 'vase' with bi-sided tucks

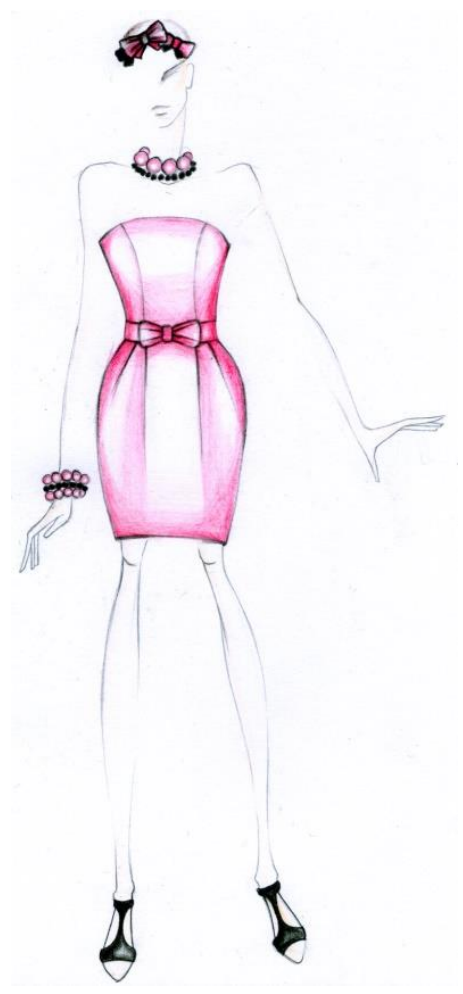

Figure 12. Silhouette 'vase' with one-sided tucks

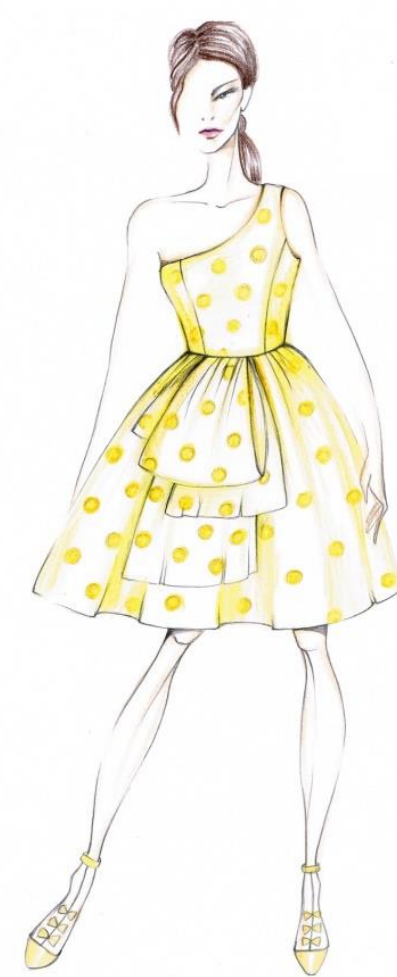

Figure 10. Silhouette 'flower' with intensive gather and big ribbon

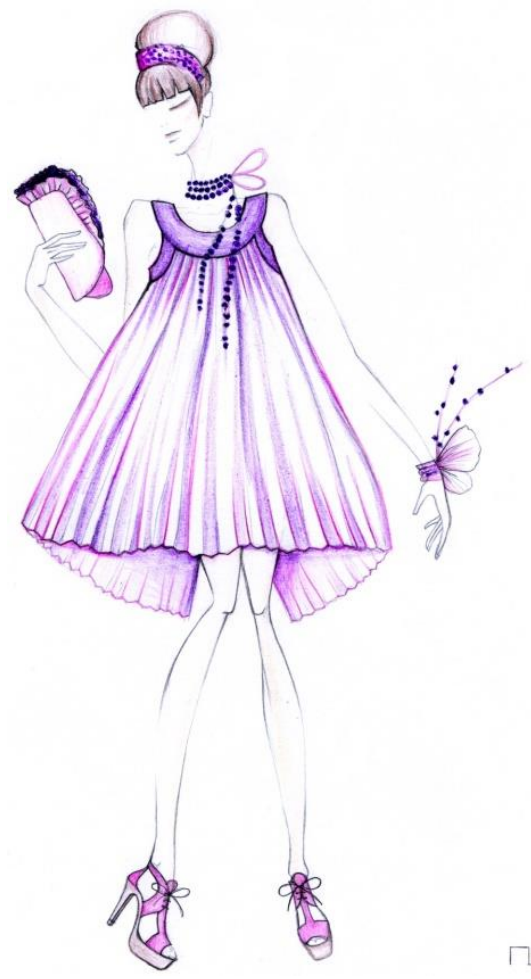

Figure 13. A silhouette with goffers

IRTIIE Vol. 4, No. 2, 2016 ISSN 1314-8788 (print), ISSN 1314-8796 (online), doi: 10.15547/artte.2016.02.001 


\section{ARTIL

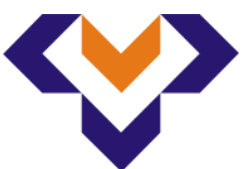 \\ Ipplied Researthes in Technics, Technologies and Bdurition \\ Journal of the Faculty of Technics and Technologies, Trakia University https://sites.google.com/a/trakia-uni.bg/artte/}

The analysis of the fashion trends since 2015 shows that some fashion brands have promoted ladies' garments in silhouettes, which can be defined by any of classified ones. [3] These unclassified silhouettes mix 2 ore 3 known silhouettes, combinations between volumetric and non-volumetric shapes, or mixtures of only volumetric ones.

Figure 14 presents a lady's dress in a silhouette which combines $Y$ shape and 'vase' form. The shape of the upper part of the model is a result of volumetric sleeves with bi-sided tucks. The form of the down part of the silhouette is got by a peplum with bi-sided tucks.

Figure15 shows a lady's dress in a silhouette which combines $Y$ shape and 'vase' form too. The shape of the upper part of the model in $Y$ silhouette is a result of volumetric sleeves with bi-sided tucks. The down volumetric part of the dress is designed by free draperies.

Figure 16 shows an asymmetric lady's dress in mixed silhouette. The shape of the down part of the dress is a result of asymmetric peplum with bi-sided tucks. The left part of the peplum is more volumetric than the right one. The form of the upper part of the dress is a result of sleeves with tucks and a big ribbon. The asymmetric shape of the dress mixes $X$ silhouette in the left part and a combination of $Y$ form and silhouette 'vase' in the right part of the model.

Figure 17 presents a model of an asymmetric lady's dress which combines $Y$ shape in the upper part and 'vase' form in the down part. The down part mixed draperies in the right and bi-sided tucks in the left.

Figure 18 presents a model of a lady's dress which mixes silhouette 'vase' in the right and combination between $Y$ shape and 'vase' in the left. The form of the right down part of the dress is designed with draperies and the form of the left down part of the model is a result of the use of tucks and ruffles.

Figure 19 shows a model of a lady's dress which mixes fitted at the waist silhouette in the right and combination between $Y$ shape and 'vase' in the left. $Y$ and 'vase' silhouette in the left are designed with ruffles.

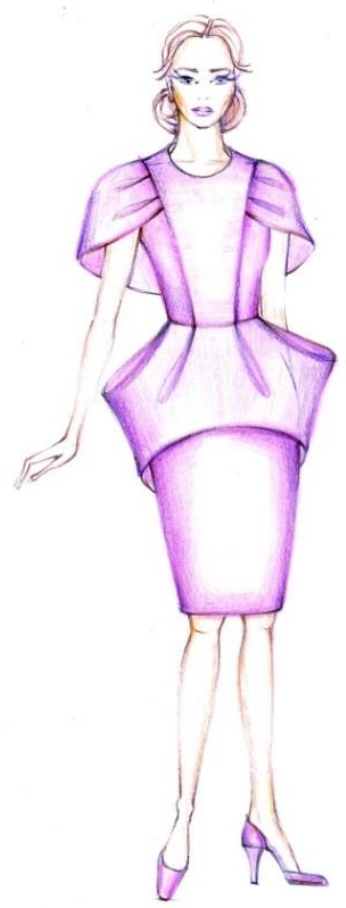

Figure 14. Mixed silhouette with bi-sided tucks in volumetric parts

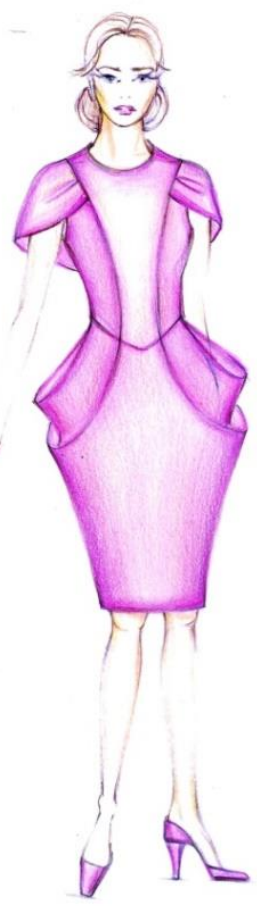

Figure 15. Combined silhouette with tucks in the upper part and draperies in the down part

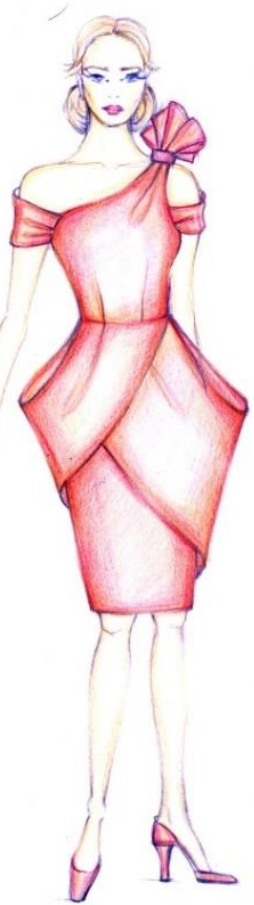

Figure 16. Mixed silhouette with a ribbon and tucks in the upper part and tucks in the down part

IRTIIE Vol. 4, No. 2, 2016 ISSN 1314-8788 (print), ISSN 1314-8796 (online), doi: 10.15547/artte.2016.02.001 


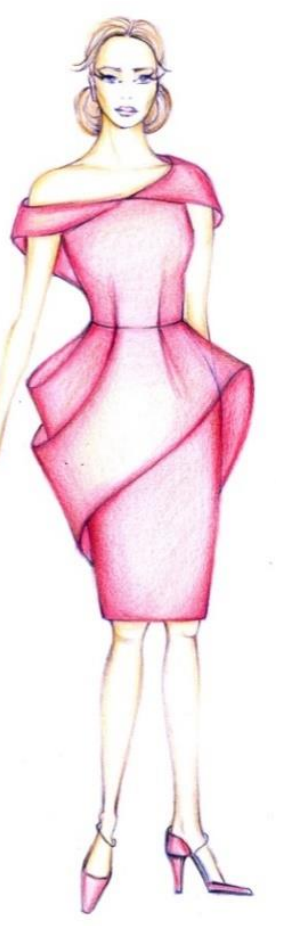

Figure 17. Mixed silhouette with draperies and tucks in the down part of the dress

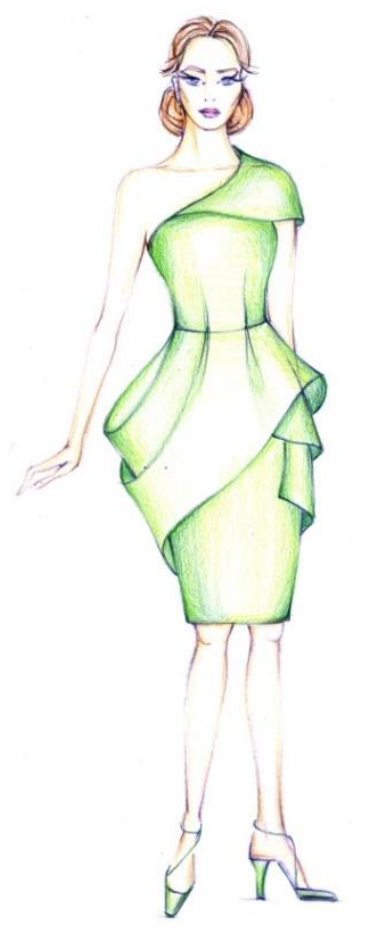

Figure 18. Mixed silhouette with draperies and ruffles in the down part of the dress

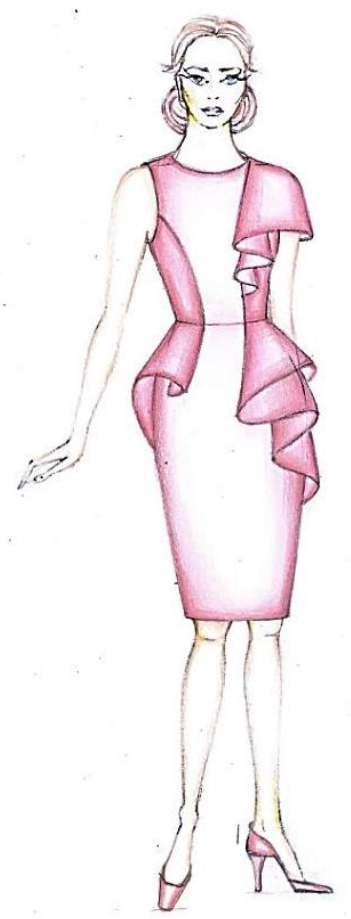

Figure 19. Combined silhouette with ruffles in the left part of the dress

\section{CONCLUSIONS}

One more silhouette - combined one can be added to the classification of the silhouettes. This type of silhouette can be combination between volumetric and non-volumetric shapes, or mixture of only volumetric ones.

Every type of 3D elements can be used in design of volumetric silhouettes. And these types are: draperies; one-sided, bi-sided, and covered tucks; gathers, one-sided, bi-sided, and covered plates; goffers; ruffles; ribbons.

3D elements can be used in the fashion design of different types of silhouettes as elements which combined decorative and constructional function, or as only decorative ones.

\section{ACKNOWLEDGEMENTS}

The work is supported by the scientific project 2.FTT/ 2016 of Trakia University and the Fund of the National budget for scientific research in higher education in Bulgaria.

\section{REFERENCES}

[1] Kazlacheva Z. (2007). Silhouettes in the Ladies Outer Garments. Tekstil i Obleklo, Vol. 55, No. 9, pp. 8-11, 2007.

[2] Kazlacheva Z. (2012). Design and Pattern Making of Ladies' Dresses in Different Silhouettes. Trakia University, Faculty of Technics and Technologies, 2012, ISBN 978-9549999-81-5.

[3] Ilieva J. (2016). Investigations of Connections between Colors and Forms in Textile and Fashion Design. PhD Thesis. Ruse, University of Ruse "Angel Kanchev", 2016. 